\title{
Peran Mediasi Competitive Advantage pada Pengaruh antara Learning Orientation dengan Organization Performance
}

\author{
Kadarusman ${ }^{1 *)}$, Hanif Mauludin ${ }^{2}$ \\ ${ }^{1 * 2)}$ Program Studi Akuntansi, STIE Malangkucecwara Malang, Jawa Timur 65142 \\ E-mail: kadarusman@stie-mce.ac.id ${ }^{1 *}$
}

\begin{abstract}
ABSTRAK
Penelitian ini bertujuan untuk menguji peran dari competitive advantage sebagai variabel median pada pengaruh antara learning orientation dengan organization performance. Penelitian dilakukan pada UKM (Usaha Kecil Menengah) di Kota Malang sebanyak 150 UKM dan dari kuesioner yang disebarkan yang layak di analisis sebanyak 134 kuesioner, yang dianalisis menggunakan program SmartPls. Hasil penelitian menunjukkan bahwa pengaruh antara learning orientation terhadap organization performance pada total effects menunjukan nilai $\beta=0,511$ dengan nilai $\mathrm{t}=7,370>1,86$ ( $\mathrm{t}$ tabel $\alpha=5 \%$ ) secara statistik berpengruh dan signifikan. Learning orientation juga berpengaruh positif terhadap competitive advantage dengan koefisien $\beta=0,670$ dan nilai $\mathrm{t}=7,889>1,86$ ( $\mathrm{t}$ tabel $\alpha=5 \%$ ). Competitive advantage juga berpengaruh positif terhadap organization performance dengan $\beta=$ 0,248 dan nilai $\mathrm{t}=2,501>1,86$ ( $\mathrm{t}$ tabel dengan $\alpha=5 \%$ ). Competitive advantage terbukti memediasi pengaruh antara learning organization terhadap organization performance dengan nilai koefisien $\beta$ pada total effects sebesar 0,511 dan nilai $\mathrm{t}=$ $7,370>1,86(\mathrm{t}$ tabel pada $\alpha=5 \%)$ dengan sifat mediasi parsial.
\end{abstract}

Kata kunci: Competitive advantage; learning orientation; organization performance

\begin{abstract}
This research is intended to discuss the role of competitive advantage as a median variable between learning orientation and organizational performance. The research was conducted on SMES (small medium Enterprises) in Malang City as much as 150 SMES and from the questionnaires that were disseminated in analysis as many as 134 questionnaires, which were analyzed using SmartPls 2 program. The results showed that the effect of learning orientation on organization performance on total effects showed a value of $\beta=0,511$ with a value of $t=7,370$ $>1,86$ ( t table $\alpha=5 \%$ ) statistically significantly affected. Learning orientation also has a positive effect on competitive advantage with the coefficient $\beta=0,670$ and the value of $t=7,889>1,86$ ( $t$ table $\alpha=5 \%$ ). Competitive advantage also has a positive effect on organizational performance with $\beta=0,248$ and $t$ value $=2,501>$ $1,86(t$ table with $\alpha=5 \%)$. Competitive advantage is proven to mediate the effect of learning organization on organizational performance with a coefficient $\beta$ on total effects of 0,511 and $t=7,370>1,86(t$ table at $\alpha=5 \%$ ) with partial mediation.
\end{abstract}

Keyword: Competitive advantage; learning orientation; organization performance

\section{PENDAHULUAN}

Persaingan yang ketat, ledakan teknologi informasi dan munculnya ekonomi berbasis pengetahuan, harapan konsumen yang semakin tinggi membentuk lingkungan bisnis baru 
yang sangat berbeda dengan sebelumnya. Perubahan lingkungan yang sangat cepat dan cenderung bergejolak mengharuskan organisasi mengoptimalkan sumber daya yang dimiliki melalui upaya mensinergikan sumber daya dalam bentuk strategi dan platform bisnis yang baru berdasarkan munculnya peluang pasar baru (Grande, Madsen, and Borch, 2011). Penerapan strategi perusahaan yang tercermin pada orientasi strategi sangat mempengaruhi keberhasilan suatu organisasi. Orientasi kewirausahaan, orientasi pembelajaran, orientasi pasar dan orientasi tehnologi adalah orientasi strategi perusahaan yang merupakan sumber daya yang harus dioptimalkan dalam pencapaian tujuan organisasi (Liu, Hou, Yang, and Ding, 2011). Perusahaan juga selalu dituntut untuk mencari peluang baru melalui pengembangan produk dan pasar. Sedangkan menurut Stam and Elfring (2008), yang dimaksud orientasi strategi adalah sumber daya yang diidentifikasi sebagai penentu kinerja yang unggul bagi organisasi.

Salah satu orientasi strategi bagi organisasi adalah orientasi pembelajaran. organisasi yang unggul di masa depan adalah organisasi yang mampu menemukan bagaimana cara memanfaatkan komitmen dan kapasitas anggota organisasi untuk belajar secara terus menerus di semua tingkatan organisasi (Chaston and Sadler, 2012). Perusahaan perlu secara terus menerus menciptakan kondisi, sistem, dan struktur organisasi yang mengarah pada perolehan dan penerapan pengetahuan baru yang efektif melalui pembelajaran. Perusahaan yang secara terus-menerus dapat melakukan inovasi dalam proses bisnis dan produk baru mempunyai kemungkinan lebih besar untuk dapat mempertahankan dan meningkatkan keunggulan kompetisi (Chahal and Bakshi, 2015). Kemampuan dalam organisasi pembelajar (learning organization) dapat menghasilkan kompetensi unik dari para karyawan yang mendorong menciptakan dan mengembangkan kinerja bisnis melalui pengetahuan (Chahal and Bakshi, 2015).

Organisasi pembelajar (learning organization) memusatkan pada bagaimana memperoleh pengetahuan yang bermanfaat bagi perusahaan yang dapat memperbaiki pengetahuan rutin agar keluar dari rutinitas sehingga lingkungan internal semakin dinamis dan berkembang. Orientasi pembelajaran dapat mendukung pembaharuan dalam lingkungan internal perusahaan sehingga sumberdaya internal perusahaan dapat lebih terintegrasi sebagai salah satu aspek penting dalam strategi perusahaan (Wang, 2008). Kemampuan bertindak secara unggul dalam menghadapi persaingan merupakan kompetensi utama perusahaan melalui kepemilikan dan penggunaan pengetahuan khusus dalam berbagai tahapan bisnis (Kadarusman, Surachman, Troena, dan Ratnawati, 2019). Pengembangan learning organization yang konsisten dapat secara terus menerus melakukan inovasi sehingga 
sumberdaya perusahaan tidak mudah ditiru oleh pesaing (Kadarusman et al., 2019). Organisasi yang belajar lebih baik atau lebih efektif daripada pesaingnya dapat menjadi organisasi yang meningkat lebih cepat, mempunyai kesempatan lebih baik dalam inovasi produk, peningkatan pangsa pasar sehingga dapat meningkatkan keunggulan kompetisi (Baker and Sinkula, 2009).

Learning organization merupakan organisasi yang terus mendorong dan memfasilitasi semua anggotanya untuk terus belajar dan selalu melakukan perubahan-perubahan dalam organisasi (Pedler, Boydell, and Burgayne, 1989). Organisasi pembelajar merupakan organisasi yang mempunyai filosofi untuk antisipasi, bereaksi dan menanggapi perubahan, ketidakpastin dan kompleksitas. Perusahaan yang berkembang harus mempunyai komitmen untuk terus belajar dalam mengembangkan sumber daya dan kemampuannya terkait dengan proses bisnis utamanya (Amin, 2015). Perusahaan yang kurang atau tidak berorientasi pada pembelajaran dimungkinkan akan memiliki sedikit inovasi dibanding pesaingnya (Zhao, $\mathrm{Li}$, Lee, and Chen, 2011) dan dimungkinkan akan mendapatkan kesulitan untuk bertahan hidup.

Penelitian terdahulu menunjukkan pengaruh yang signifikan antara learning organization dengan organization performance (Hussein, Mohamad, Noordin, dan Ishak, 2014; Kadarusman et al., 2019; Zhang, Zhang, and Yang, 2004). Learning organization diukur dengan 7 dimensi yaitu pembelajaran berkelanjutan (continuous learning), dialog dan penyelidikan (dialogue and inquiry), pembelajaran tim (team learning), melekat pada sistem (embedded system), sistem koneksi (system connections), pemberdayaan (empowerment), dan kepemimpinan (leadership) (Victoria J. Marsick, 2009; Yang, Watkins, and Marsick, 2004). Sedangkan menurut Akhtar, Arif, Rubi, and Naveed, (2012) dari ketuju dimensi yang ada hanya dimensi (dialogue and inquiry) dan (system connections) yang berpengaruh signifikan terhadap organization performance. Masih adanya celah penelitian diatas mendorong untuk melakukan penelitian dengan memasukkan variabel competitive advantage sebagai variabel mediasi.

Orientasi pembelajaran adalah proses mentransfer informasi dan pengetahuan pasar individu ke organisasi sehingga dapat digunakan oleh semua departemen untuk melakukan kinerja yang unggul (Sinkula, Baker, and Noordewier, 1997). Orientasi pembelajaran adalah proses mendapatkan dan mendistribusikan informasi tentang permintaan pelanggan, fluktuasi pasar, dan kegiatan pesaing disemua departemen organisasi (Hassan, Qureshi, Hasnain, Sharif, dan Hassan, 2013). Sinkula et al., (1997) berpendapat bahwa orientasi belajar menunjukkan intensitas interaksi suatu organisasi dengan lingkungan internal dan eksternal. Menurut mereka, ada tiga dimensi orientasi belajar yaitu: (1) komitmen untuk belajar 
(commitment to learn), (2) pandangan terbuka (open-mindedness) dan (3) visi bersama (shared vision). Komitmen untuk belajar berarti semua karyawan harus loyal untuk mendapatkan tujuan organisasi. Tenaga kerja organisasi harus dirangsang untuk mengembangkan ide-ide inovatif baru yang mungkin memiliki efek positif pada kinerja organisasi. Open-Mindedness melibatkan evaluasi terus menerus terhadap operasi organisasi. Ini melibatkan penerimaan ide-ide baru dengan cepat karena devolusi pengetahuan sedang tinggi sekarang. Visi Bersama mencakup berbagi visi dan tujuan organisasi disemua departemen.

Competitive advantage merupakan konsep implementasi strategi yang pada saat ini tidak dilaksanakan oleh perusahaan pesaing (Barney, 1991), sedangkan kinerja secara umum dikonseptualisasikan sebagai hasil yang diperoleh suatu organisasi dari hasil dalam mengimplementasikan strategi (Scott, 2008). Perusahaan yang telah mencapai competitive advantage merupakan perusahaan yang telah mendapatkan manfaat ekonomi lebih banyak dibanding pesaingnya. Keunggulan ekonomi bisa terjadi jika perusahaan menproduksi produk yang mempunyai manfaat lebih baik dengan biaya yang sama (differensiasi) atau produk yang mempunyai manfaat yang sama tetapi dengan biaya yang rendah (keunggulan biaya) (Scott, 2008). Perusahaan yang mempunyai keunggulan kompetisi dibanding pesaing harus dapat menjual barang dalam jumlah yang lebih banyak dengan margin yang sama atau menjual unit yang sama dengan harga yang lebih tinggi (Porter and Millar, 1985).

Orientasi pembelajaran mengacu pada kegiatan organisasi dalam mendapatkan dan menggunakan pengetahuan untuk meningkatkan competitive advantage, termasuk memperoleh dan berbagi informasi tentang kebutuhan pelanggan, perubahan pasar, dan tindakan pesaing, serta pengembangan teknologi baru untuk menciptakan produk baru yang lebih unggul dibanding pesaing (Calantone, Tamer, and Yushan, 2002). Learning orientation merupakan nilai organisasi yang mempengaruhi sejauh mana suatu organisasi merasa puas terhadap apa yang dilakukan saat ini dan bagaimana organisasi proaktif untuk melakukan pembelajaran. Learning orientation merupakan suatu proses bagaimana menghadapi informasi yang dimiliki saat ini, menafsirkan, mengvaluasi dan akhirnya meutuskan menerima atau menolak terhadap adanya informasi.

Komponen inti dari learning orientation adalah komitmen untuk belajar (commitment to learn), pandangan terbuka (open-mindedness) dan visi bersama (shared vision) (Sinkula et al., 1997; Wang, 2008). Commitment to learn sejauh mana organisasi mempunyai komitmen untuk belajar dan memberi kesempatan kepada anggota organisasinya untuk belajar, komitmen untuk menumbuhkan iklim belajar. Organisasi yang menghargai pembelajaran 
semakin besar pembelajaran organisasi akan terjadi. Pandangan terbuka (open-mindedness) merupakan kesediaan dari organisasi mnegevaluasi secara kritis kegiatan rutinitas operasional dan menerima ide-ide baru. Kesadaran dari organisasi tentang kemungkinan keusangan pengetahuan yang dimiliki karena berubahnya tehnologi dan perubahan pasar yang sangat cepat. Visi bersama (share vision) merupakan fokus organisasi pada orientasi pembelajaran oleh anggota organisasi. Pembelajaran anggota organisasi tidak menjadi bermakna kecuali adanya visi bersama, karena gagasan hebatpun tidak bisa diterjemahkan ke dalam tindakan tanpa adanya visi bersama. Iklim belajar yang positif memutuhkan visi bersama ketika pengetahuan baru akan dilaksanakan (Calantone et al., 2002; Wang, 2008).

Konsep kinerja organisasi didasarkan pada gagasan bahwa sebuah organisasi merupakan sekumpulan asset produktif, termasuk sumber daya manusia, fisik, modal untuk mencapai tujuan bersama. Penyedia asset hanya akan berkomitmen kepada organisasi apabila mereka merasa puas terhadap imbalan yang mereka peroleh relatif terhadap penggunaan asset alternative. Pemahaman tentang ukuran kinerja yang berbeda sangat penting dalam rangka mengintegrasikan dimensi kinerja organisasi yang berbeda. Kinerja adalah konsep multidimensi dan kinerja dapat bergantung pada indikator yang digunakan untuk menilai kinerja (Gregory and Lumpkin, 2005). Literatur empiris melaporkan keragaman yang tinggi dari indikator kinerja, dengan perbedaan yang umum adalah antara ukuran finansial dan nonfinansial. Ukuran nonfinansial mencakup tujuan seperti kepuasan dan peringkat global yang sukses dibuat oleh pemilik atau manajer bisnis; ukuran keuangan meliputi penilaian dari faktor-faktor seperti pertumbuhan penjualan dan laba atas investasi. Performance diukur dalam satu atau kombinasi dari tiga cara berikut: persepsi keuangan, persepsi non-keuangan dan data keuangan (Rauch, Wiklund, Lumpkin, and Frese, 2009).

Penelitian ini organization performance diukur dengan tiga dimensi yaitu efficiency, growht dan profit, dimana masing-masing dimensi diukur dengan 3 indikator. Indikator masing-masing dimensi adalah sebagai berikut: pertama, dimensi efisiensi diukur dengan 3 item, yaitu return on investment, return on equity dan return on asset. Kedua, dimensi growht diukur dengan 3 item, yaitu persepsi pertumbuhan penjualan, pertumbuhan karyawan dan pangsa pasar. Ketiga, adalah dimensi profit yang diukur dengan 3 item juga, yaitu return on sales, net profit margin, and gross profit margin (Kadarusman et al., 2019; Li, Huang, and Tsai, 2008).

Competive advantage merupakan kemampuan suatu organisasi untuk mendapatkan pengembalian investasi diatas rata-rata industri secara konsisten (Porter, 1985). Sedangkan Barney (1991) berpendapat bahwa competitive advantage hanya dapat dicapai jika organisasi 
dapat menerapkan strategi penciptaan nilai yang tidak dapat dilakukan oleh pesaing saat ini atau pesaing potensial. Competitive advantage merupakan strategi yang dapat dikendalikan sehingga organisasi dapat merumuskan merumuskan dan mengimplementasikan strategi secara efisien dan efektif. Keunggulan kompetitif umumnya dikonseptualisasikan sebagai implementasi strategi yang saat ini tidak dilaksanakan oleh perusahaan lain yang memfasilitasi pengurangan biaya, eksploitasi peluang pasar, dan/atau netralisasi ancaman kompetitif (Barney, 1991), kinerja umumnya dikonseptualisasikan sebagai sewa yang diperoleh perusahaan sebagai hasil dari implementasi strateginya (Helfat and Peteraf, 2009).

Berdasarkan latar belakang dan pengembangan teori diatas maka penelitian ini mengajukan model penelitian sebagai berikut:

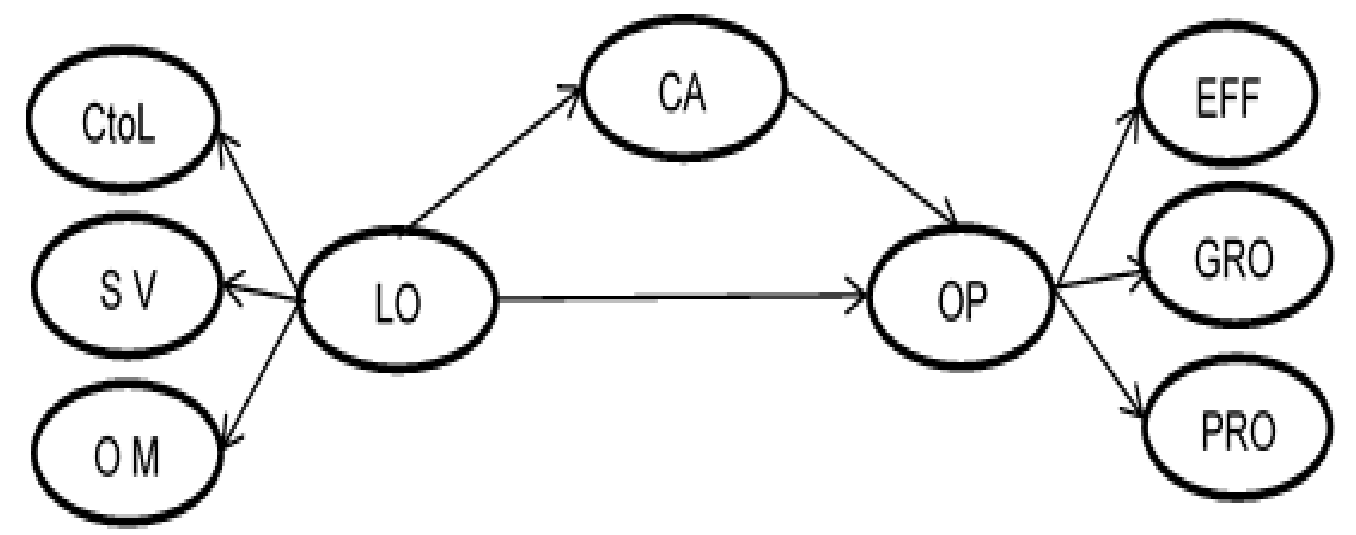

Gambar 1. Model Penelitian

Sumber: 1. (Amin, 2015; Wang, 2008), 2. (Calantone et al., 2002; Hakala, 2013), 3. (Porter, 1985)

Keterangan:

LO = Learning Orientation,

$\mathrm{C}$ to $\mathrm{L}=$ Continouse to Learning,

$\mathrm{SV}=$ Share Vision,

$\mathrm{O} \mathrm{M}=$ Open-Mindness,

$C A=$ Competitive Advantage,

$\mathrm{OP}=$ Organization Performance,

$\mathrm{EFF}=$ Efficiencies,

GRO = Growht,

$\mathrm{PRO}=$ Profit

Kofman and Senge, (1993) menyatakan bahwa learning organization adalah organisasi yang mempunyai kapasitas unik yang mencakup keterampilan dan pengetahuan, yang dilakukan melalui proses organisasi dan koordinasi berbagai kegiatan dan memanfaatkan asetnya. Kapasitas yang unik memiliki beberapa persyaratan, termasuk: (1) untuk 
berkontribusi secara tidak proporsional dengan nilai unggul, (2) memungkinkan organisasi untuk menawarkan nilai kepada pelanggan dengan lebih hemat biaya, (3) unggul dengan pesaingnya, (4) sulit diduplikasi pesaing; dan (5) dapat diterapkan untuk berbagai situasi kompetitif (Mauludin, Alhabsji, Idrus, dan Arifin, 2013). Learning orientation menjadikan individu yang ada dalam organisasi terus belajar dan terus menerus melakukan penyesuaian dengan perubahan lingkungan unutuk meningkatkan organization performance.

Organisasi yang berorientasi pembelajaran dapat merespon lebih baik dan lebih cepat terhadap perubahan teknologi dan perkembangan baru. Selain itu, orientasi pembelajaran meningkatkan tingkat kepuasan karyawan dan pelanggan potensial yang mengarah pada profitabilitas organisasi yang lebih tinggi. Menurut Calantone et al., (2004) organisasi yang berorientasi pembelajaran memiliki pengetahuan yang cukup tentang pelanggan, saingan, dan teknologi terbaru. Selain itu, orientasi pembelajaran memfasilitasi visi dan komunikasi bersama atas fakta-fakta pasar di semua departemen, sehingga dalam penelitian ini dikembangkan hipotesis pertama dan kedua adalah sebagai berikut:

$\mathrm{H} 1$ : learning orientation berpengaruh positif terhadap organization performance

$\mathrm{H} 2$ : Learning orientation berpengaruh positif terhadap competitive advantage

H3: Competitive advantage berpengaruh positif terhadap organization performance.

Competitive advantage sebagai variabel mediasi pengaruh antara learning orientation terhadap organization performance.

Competitive advantage dan organization performance merupakan konsep yang seringkali digunakan secara bergantian, dimana yang satu mendukung yang lain, tetapi menurut Scott (2008), kedua variabel tersebut merupakan variabel yang berbeda. Competitive advantage merupakan konsep implementasi strategi yang pada sat yang sama tidak dilaksankan oleh pesaing sedangkan organization performance merupakan hasil dari penerapan strategi tertentu. Perusahaan yang mempunyai kecenderungan untuk belajar mempunyai kemungkinan untuk menjadi lebih baik dibanding pesaingnya. Sehingga penelitian ini memasukkan competitive advantage sebgai variable mediasi dan hipotesisnya adalah sebagai berikut:

H4: Pengaruh learning organization terhadap organization performance dimediasi oleh competitive advantage

\section{METODE PENELITIAN}

Penelitian ini menggunakan 3 variabel laten yaitu learning orientation, competitive advantage dan organization performance. Variabel learning orientation diukur second order 
dengan 3 dimensi, yaitu dimensi commitment to learn diukur dengan 4 indikator, dimensi share vision diukur dengan 4 indikator dan open-mindedness diukur dengan 3 indikator (Wang, 2008). Competitive advantage diukur dengan 10 indikator (Porter, 1985) sedangkan organization performance diukur dengan second order yang terdiri dari 3 dimensi, yaitu dimensi efficiency, growht dan profit yang masing-masing diukur dengan 3 dimensi (Kadarusman et al., 2019; Li et al., 2008). Indikator ketiga variabel dan masing-masing dimensi tersebut secara lengkap adalah sebagai berikut:

\section{Tabel 1. Definisi Operasional Variabel}

\begin{tabular}{|c|c|c|}
\hline Variabel laten & Dimensi & Indikator/item \\
\hline \multirow{7}{*}{$\begin{array}{l}\text { Learning } \\
\text { orientation } \\
\text { (Wang, 2008) }\end{array}$} & $\begin{array}{l}\text { Commitment to } \\
\text { Learn }\end{array}$ & $\begin{array}{l}\text { 1. Kemampuan organisasi untuk belajar adalah kunci keunggulan } \\
\text { kompetisi }\end{array}$ \\
\hline & & $\begin{array}{l}\text { 2. Nilai-nilai dasar organisasi dalam belajar adalah kunci untuk } \\
\text { perbaikan } \\
\text { 3. Pembelajaran karyawan adalah investasi bukan biaya } \\
\text { 4. Belajar merupakan komoditas utama untuk menjamin } \\
\text { kelangsungan hidup }\end{array}$ \\
\hline & Share vision & 1. Adanya kesamaan tujuan dalam organisasi \\
\hline & & $\begin{array}{l}\text { 2. Ada kesepakatan pada visi organisasi pada semua tingkatan. } \\
\text { 3. Semua karyawan berkomitmen pada tujuan organisasi } \\
\text { 4. Karyawan memandang diri mereka sebagai mitra dalam } \\
\text { menentukan arah perusahaan }\end{array}$ \\
\hline & Open-mindedness & $\begin{array}{l}\text { 1. Karyawan bisa merefleksikan secara kritis tentang pelanggan } \\
\text { perusahaan }\end{array}$ \\
\hline & & $\begin{array}{l}\text { 2. Karyawan menyadari bahwa harus secara terus menerus } \\
\text { memperbaruhi cara pandang terhadap pelanggan }\end{array}$ \\
\hline & & $\begin{array}{l}\text { 3. Karyawan sering mempertanyakan tentang bagaimana } \\
\text { organisasi menginterpretasikan informasi pelanggan }\end{array}$ \\
\hline \multirow{9}{*}{$\begin{array}{l}\text { Competitive } \\
\text { advantage } \\
\text { (Porter, 1985) }\end{array}$} & Kemampuan & 1. Pertumbuhan aset perusahaan \\
\hline & menghasilkan & 2. Kemampuan berkompetisi \\
\hline & produk/jasa yang & 3. Biaya produksi yang lebih rendah dari pesaing \\
\hline & lebih baik & 4. Keunikan produk \\
\hline & dibanding pesaing & 5. Kemampuan menghadapi ancaman pendatang baru \\
\hline & serta dapat & 6. Kemampuan menghadapi kekuatan tawar menawar konsumen \\
\hline & menghadapi & 7. Kemampuan menghadapi kekuatan tawar pemasok \\
\hline & ancaman dari & 8. Kemampuan menghadapi ancaman produkpengganti \\
\hline & pesaing potensial. & $\begin{array}{l}\text { 9. Kemampuan menghadapi ancaman dari pesaing yang saat ini } \\
\text { ada }\end{array}$ \\
\hline \multirow{9}{*}{$\begin{array}{l}\text { Organization } \\
\text { performance } \\
\text { (Kadarusman, et } \\
\text { al., 2019; Li, et } \\
\text { al., 2008) }\end{array}$} & Efficiency & 1. Perusahaan puas terhadap ROI dibanding pesaing \\
\hline & & $\begin{array}{l}\text { 2. Perusahaan puas terhadap ROE yang diperoleh dibanding } \\
\text { pesaing }\end{array}$ \\
\hline & & $\begin{array}{l}\text { 3. Perusahaan puas terhadap ROA yang diperoleh dibanding } \\
\text { pesaing }\end{array}$ \\
\hline & Growht & 1. Perusahaan puas terhadap pertumbuhan penjualan \\
\hline & & 2. Perusahaan puas terhadap pertumbuhan karyawan \\
\hline & & 3. Perusahaan puas terhadap pertumbuhan pangsa pasar \\
\hline & 4. Profit & 1. Perusahaan puas terhadap laba atas penjualan \\
\hline & & 2. Peusahaan puas terhadap laba kotor yang diperoleh \\
\hline & & 3. Perusahan puas terhadap laba bersih yang diperoleh \\
\hline
\end{tabular}

Tehnik analisis yang dipakai pada penelitian ini dengan menggunakan program SmartPls 2 dengan dua model pengujian, yaitu model pengukuran (outer model) dan model struktural (inner model). Model pengukuran (outer model) dalam penelitian ini menggunakan 
Uji validitas. Uji validitas merupakan uji yang digunakan untuk memastikan bahwa indikator yang digunakan dalam menilai variabel mampu dipahami dengan baik oleh responden, sehingga responden tidak salah pengertian dalam mengisi kuesioner. Pengujian validitas menggunakan dua alat uji yaitu convergen validity dan discriminant validity.

Convergen validity diukur dengan menggunakan nilai loading factor, dan dikatakan valid jika nilai loading factor > 0,7 (Hair., Black, Babin, and Anderson, 2009). Discriminant validity dinilai dengan cross loading yaitu membandingkan nilai loading factor dari masingmasing indikator terhadap variabel latennya harus lebih besar dibanding nilai loading factor indikator tersebut dengan variabel lainnya. Disamping itu discriminant validity juga bisa diukur dengan Average variance extracted (AVE) merupakan Koefisien yang menggambarkan interkorelasi internal yaitu rata-rata korelasi antar item di dalam model. Kriteria nilai average variance extracted (AVE) dikatakan valid jika nilai AVE > 0,5 (Hair. et al., 2009; Joseph F. Hair, Hult, Ringle, and Sarstedt, 2017).

Uji reliabilitas untuk menentukan apakah alat ukur telah melakukan fungsinya untuk mengukur secara handal dan akurat. Reliabilitas ini diukur dengan Composite reliability dikatakan reliable jika nilanya $>0,7$ dan cronbach alpha $>0,5$, menunjukan bahwa masingmasing item (indikator) dari masing-masing variabel laten mempunyai nilai korelasi yang tinggi.

Pengujian inner model dengan $U j i \mathrm{R}$ - square, Prediction relevance $\left(Q^{2}\right)=1-\left(1-\mathrm{R} 1^{2}\right)$ $\left(1-\mathrm{R} 2^{2}\right) \ldots\left(1-\mathrm{Rn}^{2}\right)$, Uji ini digunakan untuk menilai goodness of fit dari model yang diusulkan dalam penelitian. Nilai R-square dan Prediction relevance $\left(Q^{2}\right)$ di katakan baik jika nilainya $>0$ dan semakin tinggi semakin baik.

Pengujian GoF (goodness of Fit), Pengujian ini untuk menilai robust atau kuat tidaknya model yang dibentuk dlam penelitian. Nilai Goodness of Fit diukur dengan rumus sebagai berikut: $\mathrm{GoF}=$ akar rata-rata AVE $\mathrm{x}$ rata-rata $\mathrm{R}^{2}$, dimana nilai goodness of fit kecil $=0,1$ medium $=0,25$ dan besar $=0,38$ (Tenenhaus, Vinzi, Chatelin, and Lauro, 2005). Uji hipotesis, digunakan untuk menguji hipotesis yang diajukan dalam penelitian, yang meliputi uji parsial dan mediasi.

\section{HASIL DAN PEMBAHASAN}

Data diperoleh dengan menyebarkan kuesioner pada usaha kecil menengah sebanyak 150 Usaha Kecil Menengah di Malang, yang merupakan Usaha Kecil Menengah (UKM) di Kota Malang. Dari 150 kuesioner yang disebarkan, sebanyak 134 kuesioner bisa dianalisis sedangkan sisanya tidak bisa dianalisis karena diisi tidak lengkap. Analisis statistik 
menggunakan program SmartPls 2. Pengujian dilakukan dengan menguji outer model, inner model dan uji hipotesis. Uji outer model ini dimaksudkan untuk menguji validitas dan reliabilitas dari indikator pengukur variabel. Adapun hasil uji validitas dan reliabilitas dapat dilihat di tabel berikut ini:

Tabel 2. Pengujian Validitas dan Reliabilitas

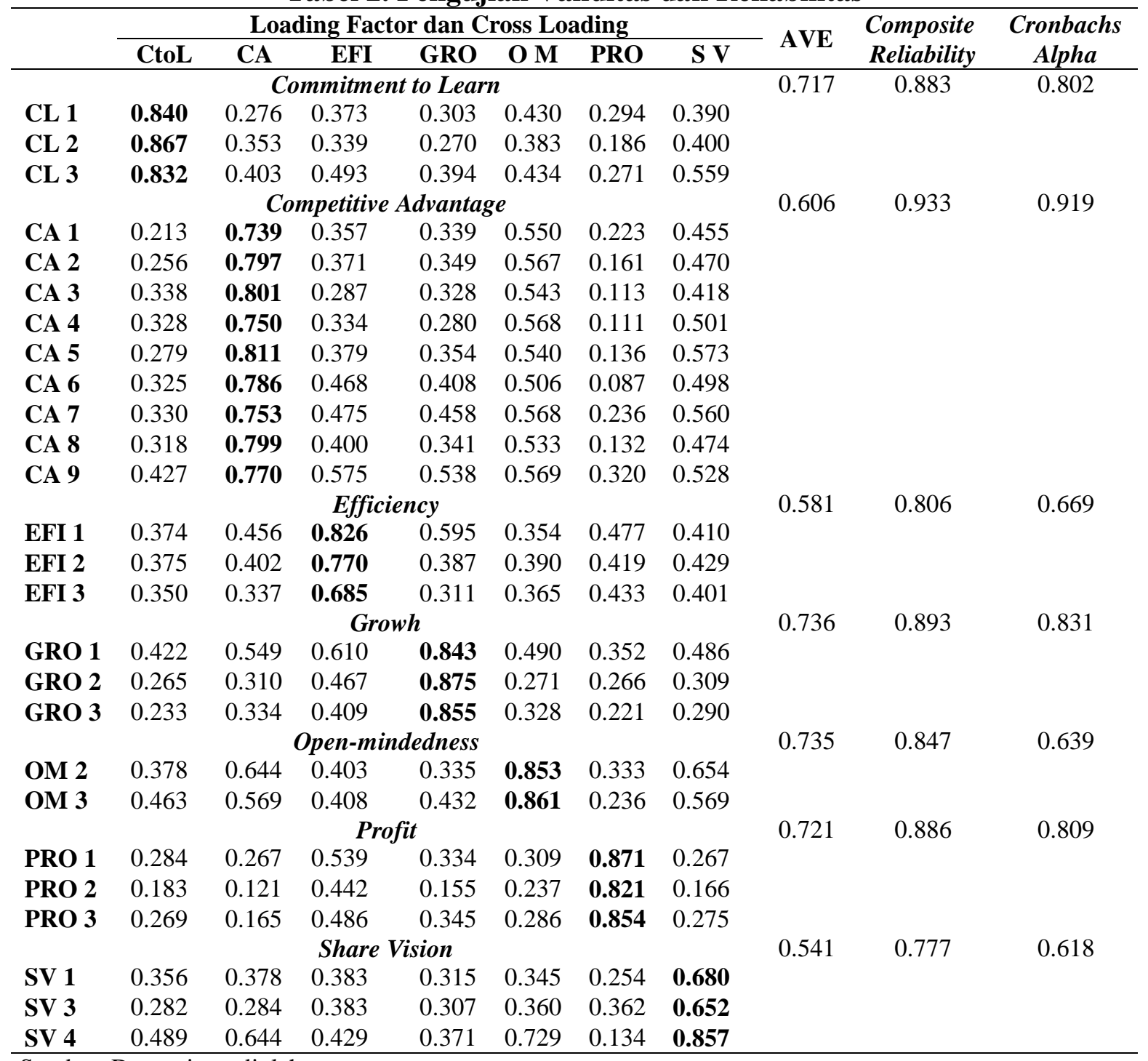

Sumber: Data primer diolah

Keterangan:

CtoL = Commitment to learn,

$\mathrm{CA}=$ Competitive advantage,

$\mathrm{EFI}=$ Efficiency,

GRO = Growth,

$\mathrm{OM}=$ Open mindedness,

$\mathrm{PRO}=$ Profit,

$\mathrm{SV}=$ Shared vision

Berdasarkan tabel 2 dapat dilihat bahwa nilai loading factor dari masing-masing variabel dan dimensi lebih besar dari 0,7, hanya indikator efficiency 3 dari dimensi efficiency 
pada variabel organization performance dan indikator share vision 3 dari dimensi share vision pada variabel learning orientation yang lebih kecil dari 0,7 tetapi masih lebih besar dari 0,6 dan nilai AVE lebih besar dari 0,5. Hasil tersebut mengindikasikan bahwa indikator yang digunakan dalam penelitian ini dapat dipahami dengan baik oleh responden, sehingga responden dalam mengisi kuesioner tidak terjadi kesalahpahaman. Hasil loading faktor tersebut juga mngeindikasikan bahwa semua indikator telah menilai dimensi dan variabelnya dengan baik, karena responden memahami dengan baik kuesioner penelitian yang harus diisi. Indikator open mindness 1 (OM 1) dan share vision 2 (SV 2) di hapus dari model karena loading factor kurang dari 0,5.

Berdasarkan pengujian cross loading dapat simpulkan bahwa nilai loading factor masing-masing indikator mempunyai nilai yang lebih besar dalam dimensi dan variabelnya dibandingkan dengan nilai loading factor indikator dengan dimensi dan variabel lainnya, sehingga terjadi homogenitas masing-masing indikator dengan dimensi dan variabelnya. Nilai AVE $>0,5$ dan nilai cronbachs alpha $>0,5$ serta nilai composite reliability $>0,7$ sehingga bisa disimpulkan bahwa alat ukur telah mampu mengukur secara akurat dan tepat serta konsisten dalam melakukan fungsinya sebagai alat pengukuran. Hasil uji inner model dengan menggunakan $\mathrm{R}^{2}, \mathrm{Q}^{2}$ dan $\mathrm{GoF}$ adalah sebagai berikut:

Tabel 3. $\mathbf{R}^{2}, \mathbf{Q}^{2} \mathbf{G o F}$

\begin{tabular}{cccc}
\hline & $\boldsymbol{R}$ Square & Q Square & GoF \\
\hline CA & 0,449 & & \\
LO & - & 0,612 & 0,465 \\
OP & 0,295 & & \\
\hline
\end{tabular}

Sumber: data primer diolah

Berdasarkan tabel 3 nilai Q square 0,612 > 0,35 berarti bahwa model yang diusulkan dalam penelitin ini mempunyai daya prediksi yang kuat, sedangkan, nilai GoF 0,465 > 0,38 menunjukan nilai yang besar (Tenenhaus et al., 2005), sehingga bisa digunakan dalam pengujian hipotesis selanjutnya. Pengujian hipotesis ini digunakan hasil smartpls 2 dengan boothstrapping adalah sebagai berikut:

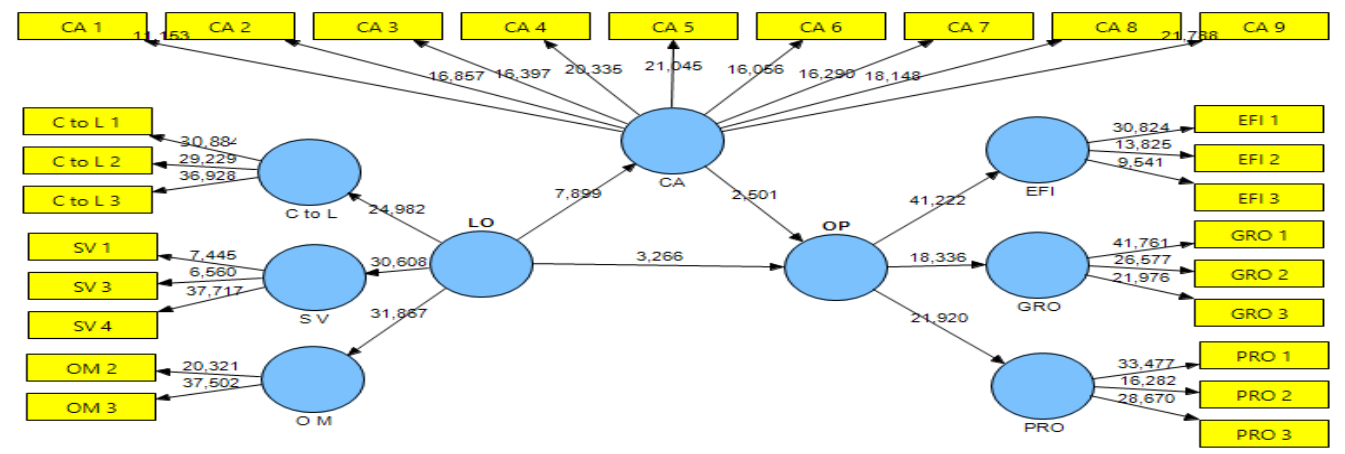

Gambar 2. Uji Boothstrapping

Sumber: data primer yang diolah 
Tabel 4. Total Effects dan Path Coefficients

\begin{tabular}{|c|c|c|c|c|c|}
\hline & $\begin{array}{c}\text { Original } \\
\text { Sample }(O)\end{array}$ & $\begin{array}{c}\text { Sample } \\
\text { Mean }(M)\end{array}$ & $\begin{array}{c}\text { Standard Deviation } \\
(S T D E V)\end{array}$ & $\begin{array}{l}\text { Standard Error } \\
\quad(\text { STERR })\end{array}$ & $\begin{array}{c}\text { T Statistics } \\
(|O / S T E R R|)\end{array}$ \\
\hline \multicolumn{6}{|c|}{ TOTAL EFFECTS } \\
\hline CA -> OP & 0,248 & 0,265 & 0,099 & 0,099 & 2,501 \\
\hline $\mathrm{LO}->\mathrm{CA}$ & 0,670 & 0,674 & 0,085 & 0,085 & 7,899 \\
\hline $\mathrm{LO}->\mathrm{OP}$ & 0,511 & 0,514 & 0,069 & 0,069 & 7,370 \\
\hline \multicolumn{6}{|c|}{ PATH COEFFICIENS } \\
\hline CA -> OP & 0,248 & 0,265 & 0,099 & 0,099 & 2,501 \\
\hline $\mathrm{LO}->\mathrm{CA}$ & 0,670 & 0,674 & 0,085 & 0,085 & 7,899 \\
\hline $\mathrm{LO}->\mathrm{OP}$ & 0,344 & 0,332 & 0,105 & 0,105 & 3,266 \\
\hline
\end{tabular}

Sumber: data primer diolah

Hipotesis pertama learning orientation berpengaruh positif terhadap organization performance. Berdasarkan tabel diatas menunjukan bahwa pengaruh antara learning orientation terhadap organization performance pada total effects menunjukan nilai $\beta=0,511$ dengan nilai $\mathrm{t}=7,370>1,86(\mathrm{t}$ tabel $\alpha=5 \%)$, berarti bahwa secara statistik hipotesis pertama diterima. Organisasi yang mempunyai keiinginan untuk belajar lebih tinggi dibanding pesaingnya dimungkinkan akan mempunyai kinerja lebih baik. Keinginan terus belajar yang ditunjukan pada keyakinan organisasi bahwa belajar adalah kunci dalam mencapai keunggulan kompetisi, belajar adalah kunci untuk perbaikan, pembelajaran karyawan merupakan investasi bukan biaya dan dengan belajar dapat menjamin kelangsungan hidup organisasi. Orientasi pembelajaran karyawan juga dapat meningkatkan komitmen karyawan dalam pencapaian tujuan organisasi, karyawan merasa sebagai mitra organisasi dalam menentukan arah perusahaan dan karyawan juga akan secara terus-menerus memperbarui cara pandang dalam memberikan layanan pada pelanggan, sehingga akan meningkatkan kinerja organisasi secara keseluruah. Hasil penelitian ini juga sejalan dengan penelitian (Akhtar et al., 2012; Calantone et al., 2002; Mauludin et al., 2013). Hasil temuan Calantone et al., (2004) menunjukan bahwa learning orientation berpengaruh positif dan signifikan terhadap organization innovation dan performance, sedangkan menurut Mauludin et al., (2013) learning organization berpengaruh positif dan signifikan terhadap value creation.

Hipotesis kedua Learning orientation berpengaruh positif terhadap competitive advantage. Koefisien $\beta$ pengaruh antara Learning orientation dengan competitive advantage adalah sebesar 0,670 dengan nilai $\mathrm{t}=7,889>1,86(\mathrm{t}$ tabel $\alpha=5 \%)$, berarti bahwa secara statistik hipotesis kedua yang dapat diterima secara signifikan dan positif. Meningkatnya keyakinan organisasi untuk terus belajar akan meningkatkan keunggulan kompetisi organisasi. Organisasi yang mempunyai orientasi untuk belajar memungkinkan organisasi tersebut mampu meningkatkan pangsa pasar, mampu meningkatkan aset, mempunyai keunggulan biaya dan produk yang berbeda dengan pesaing. Organisasi yang terus belajar 
juga dimungkinkan dapat memenangkan persaingan dengan organisasi yang saat ini ada, dapat menghadapi daya tawar baik konsumen, pemasok maupun pendatang baru potensial. Temuan penelitian ini mendukung temuan penelitian (Akhtar et al., 2012; Kadarusman et al., 2019; Zhang et al., 2004).

Hipotesis ketiga Competitive advantage berpengaruh positif terhadap organization performance. Hasil analisis statistik menunjukan bahwa nilai $\beta=0,248$ dan nilai $t=2,501>$ 1,86 ( $\mathrm{t}$ tabel dengan $\alpha=5 \%$ ), berarti bahwa competitive advantage berpengaruh positif dengan organization performance. Kemampuan organisasi untuk mendapatkan pangsa pasar yang lebih tinggi, meningkatnya aset, didukung dengan biaya yang rendah serta produk yang berbeda dengan pesaing merupakan indikasi meningkatnya kinerja organisasi yang dimungkinkan ditandai dengan meningkatnya baik itu pertumbuhan, efisiensi maupun profit organisasi. Organisasi yang mampu menghadapi masuknya pesaing baru, menghadapi kekuatan tawar konsumen maupun pemasok, serta mampu mengahadapi kemungkinan adanya barang subtitusi akan cenderung mempunyai kinerja yang lebih baik. Perusahaan yang mempunyai biaya produksi yang lebih rendah dari pesaing akan cenderung mempunyai keunggulan kompetisi dibanding pesaing, karena mempunyai flesibilitas dalam menentukan harga dan kemungkinan keuntungan yang lebih besar. Perusahaan yang mempunyai keunikan produk juga diharapkan dapat meningkatkan keunggulan kompetisi karena dengan keunikan produk perusahaan dimungkinkan ada keenganan dari konsumen untuk beralih ke produk yang lain dismping itu dengan produk yang unik konsumen kemungkinan besar mempunyai switching cost yang tinggi jika harus pindah ke perusahaan lain. Penelitian ini mendukung temuan Scott, (2008), yang menyatakan bahwa bahwa competitive advantage merupakan proses implementasi strategi yang tidak dilakukan oleh pesaing sedangkan kinerja merupakan hasil dari penerapan strategi. Hasil ini juga mndukung penelitian (Mahmood dan Hanafi, 2013; Talaja, 2017) yang menyatkan bahwa competitive advantage akan mempunyai dampak pada penghasilan diatas rata-rata.

Hipotesis keempat adalah pengaruh learning organization terhadap organization performance dimediasi oleh competitive advantage. Nilai koefisien $\beta$ pada total effects untuk pengaruh antara learning orientation dengan organization performance adalah sebesar 0,511 dan nilai $\mathrm{t}=7,370>1,86(\mathrm{t}$ tabel pada $\alpha=5 \%$ ). Sedangkan nilai $\beta$ pada path coefficiens untuk pengaruh antara learning orientation dengan organization performance adalah sebesar 0,344 , dengan nilai $\mathrm{t}=3,266>1,86(\mathrm{t}$ tabel $\alpha=5 \%$ ). Nilai $\beta$ total effect sebesar 0,511 turun menjadi 0,344 pada path coefficients dan nilai t statistik sama-sama signifikan, berarti bahwa variabel competitive advantage merupakan variabel mediasi dengan sifat mediasi parsial. 


\section{KESIMPULAN DAN SARAN}

Hasil penelitian menunjukkan bahwa organisasi yang mempunyai orientasi untuk terus belajar akan meningkatkan keunggulan kompetisi dan kinerja organisasi. Organisasi yang mempunyai budaya untuk terus belajar cenderung mempunyai kinerja yang meningkat seiring meningkatnya orientasi pembelajaran organisasi. Organisasi yang mempunyai keunggulan kompetisi akan cenderung untuk dapat meningkatkan kinerja organiasi. Keunggulan kompetisi menjadi variabel mediasi yang bersifat parsial pengaruh antara learning orientation dengan organization performance. Keterbatasan dari penelitian ini adalah kuesioner diisi oleh responden dimungkinkan tidak sesuai dengan kenyataan, karena kuesioner ini bersifat persepsi atas apa yang dilakukan oleh responden. Objek penelitian ini hanya ada diwilayah Kota Malang yang dimungkinkan mempunyai karateristik yang berbeda jika dibanding dengan wilayah lain. Peneliti selanjutnya diharapkan dapat mengembangkan pada obyek penelitian ynag lebih luas lagi dan dengan memasukkan variabel lain yang belum diteliti sehingga kesimpulan dari penelitian bisa digeneralisasikan.

\section{REFERENSI}

Akhtar, S., Arif, A., Rubi, E., \& Naveed, S. (2012). Impact of Organizational Learning on Organizational Performance: Study of Higher Education Institutes. International Journal of Academic Research, 3(5), 327-331.

Amin, M. (2015). The Effect of Entrepreneurship Orientation and Learning Orientation on SMEs' Performance: an SEM-PLS approach. J. for International Business and Entrepreneurship Development, 8(3), 215. https://doi.org/10.1504/jibed.2015.070797

Baker, W. E., \& Sinkula, J. M. (2009). The Complementary Effects of Market Orientation and Entrepreneurial Orientation on Profitability in Small Businesses. Journal of Small Business Management, 47(4), 443-464. https://doi.org/10.1111/j.1540627X.2009.00278.x

Barney, J. (1991). Firm Resources and Sustained Competitive Advantage. Journal of Management, 17(1), 99-120.

Calantone, R. J., Tamer, C. S., \& Yushan, Z. (2002). Learning orientation, Firm Innovation Capability, and Firm Performance. Industrial Marketing Management, 31, 515-524.

Chahal, H., \& Bakshi, P. (2015). Examining Intellectual Capital and competitive Advantage Relationship: Role of Innovation and Organizational Learning. Marketing Intelligence and Planning, 33(3), 376-399. https://doi.org/10.1108/IJBM-07-2013-0069

Chaston, I., \& Sadler-Smith, E. (2012). Entrepreneurial Cognition, Entrepreneurial Orientation and Firm Capability in the Creative Industries. British Journal of Management, 23(3), 415-432. https://doi.org/10.1111/j.1467-8551.2011.00752.x

Grande, J., Madsen, E. L., \& Borch, O. J. (2011). The relationship between Resources, Entrepreneurial Orientation and Performance in Farm-Based Ventures. Entrepreneurship and Regional Development, 23(3-4), 89-111. https://doi.org/10.1080/08985620903183710

Gregory G. Dess, \& Lumpkin, G. T. (2005). The Role of Entrepreneurial Orientation in Stimulating Effective Corporate Entrepreneurship. Academy of Management Executive, 
19(1), 147-158. https://doi.org/10.5465/AME.2005.15841975

Hair., J., Black, W. C., Babin, B. J., \& Anderson, R. E. (2009). Multivariate Data Analysis (Seventh Ed).

Hakala, H. (2013). Entrepreneurial and Learning Orientation: Effects on Growth and Profitability in the Software Sector. Baltic Journal of Management, 8(1), 102-118. https://doi.org/10.1108/17465261311291687

Hassan, M. U., Qureshi, S. U., Hasnain, A., Sharif, I., \& Hassan, R. (2013). Market Orientation , Learning Orientation and Organizational Performance : Evidence From Banking Industry of Pakistan. Science International Lahore, 25(4), 945-956.

Helfat, C. E., \& Peteraf, M. A. (2009). Understanding Dynamic Capabilities: Progress along a Developmental Path. Strategic Organization, 7(1), 91-102. https://doi.org/10.1177/1476127008100133

Hussein, N., Mohamad, A., Noordin, F., \& Ishak, N. A. (2014). Learning Organization and its Effect On Organizational Performance and Organizational Innovativeness: A Proposed Framework for Malaysian Public Institutions of Higher Education. Procedia - Social and Behavioral Sciences, 130, 299-304. https://doi.org/10.1016/j.sbspro.2014.04.035

Joseph F. Hair, J., Hult, G. T. M., Ringle, C. M., \& Sarstedt, M. (2017). A Primer on Partial Least Squares Structural Equation Modeling (PLS-SEM) (second Edi). https://doi.org/10.1007/s10995-012-1023-x [doi]

Kadarusman, Surachman, Troena, E. A., \& Ratnawati, K. (2019). The Influence Between Entrepreneurial Orientation and Organization Performance Role-Playing Organization and Competitive Advantage as a Mediation Variable. Journal Of Engineering and Applied Science, 14(14), 4703-4712.

Kofman, F., \& Senge, P. M. (1993). Heart Learning Organizations.

Li, Y. H., Huang, J. W., \& Tsai, M. T. (2008). Entrepreneurial Orientation and Firm Performance: The Role of Knowledge Creation Process. Industrial Marketing Management, 38(4), 440-449. https://doi.org/10.1016/j.indmarman.2008.02.004

Liu, H., Hou, J., Yang, P., \& Ding, X. H. (2011). Entrepreneurial Orientation, Organizational Capability, and Competitive Advantage in Emerging Economies: Evidence from China. Afr. J. Bus. Manage, 5(10), 3891-3901. https://doi.org/10.5897/AJBM10.1080

Mahmood, R., \& Hanafi, N. (2013). Entrepreneurial Orientation and Business Performance of Women-Owned Small and Medium Enterprises in Malaysia: Competitive Advantage as a Mediator. International Journal of Business and Social Science, 4(1), 82-91. https://doi.org/10.1177/0266242612455034

Mauludin, H., Alhabsji, T., Idrus, S., \& Arifin, Z. (2013). Market Orientation, Learning Organization and Dynamic Capability as Antecedents of Value Creation. IOSR Journal of Business and Management, 10(2), 38-48. https://doi.org/10.9790/487x-1023848

Pedler, M., Boydell, T., \& Burgayne, J. (1989). The Learning Company. Studies in Continuing Education, 11(2), 91-104.

Porter, M. E. (1985). Competitive Advantage: Creating and Sustaining Superior Performance.

Porter, M. E., \& Millar, V. E. (1985). How Information Gives You Competitive Advantage. Harvard Business Review, (84208).

Rauch, A., Wiklund, J., Lumpkin, G. T., \& Frese, M. (2009). Entrepreneurial Orientation and Business Performance: An Assessment of Past Research and Suggestions for the Future. Entrepreneurship: Theory and Practice, 33(3), 761-787. https://doi.org/10.1111/j.15406520.2009.00308.x

Scott L. Newbert. (2008). Value, Rareness, Competitive Advantage, and Performance: A Conceptual-Level Empirical Investigation of The Resources-Based View of the Firm. Strategic Management Journal, 29, 745-768. https://doi.org/10.1002/smj 
Sinkula, J. M., Baker, W. E., \& Noordewier, T. (1997). A framework for market-Based Organizational Learning: Linking Values, Knowledge, and Behavior. Journal of the Academy of Marketing Science, 25(4), 305-318. https://doi.org/10.1177/0092070397254003

Stam, W., \& Elfring, T. (2008). Entrepreneurial Orientation and new Venture Performance: The Moderating Role of Intra- and Extraindustry Social Capital. Academy of Management Journal, 51(1), 97-111. https://doi.org/10.5465/AMJ.2008.30744031

Talaja, A. (2017). Testing Vrin Framework: Resource Value and Rareness As Sources Of Competitive Advantage and Above Average Performance. 64(1), 59-87.

Tenenhaus, M., Vinzi, V. E., Chatelin, Y. M., \& Lauro, C. (2005). PLS Path Modeling. Computational Statistics and Data Analysis, 48(1), 159-205. https://doi.org/10.1016/j.csda.2004.03.005

Tuan, N. P., \& Yoshi, T. (2010). Organisational Capabilities , Competitive Advantage and Performance in Supporting Industries in Vietnam. Asian Academy of Management Journal, 15(1), 1-21.

Victoria J. Marsick, K. E. W. (2009). Demonstrating the value of a Organizational Learning Culture. Advances in Developing Human Resources, 5(2), 132-151. https://doi.org/10.1177/1523422303251341

Wang, C. L. (2008). Entrepreneurial Orientation, Learning Orientation, and Firm Performance. Entrepreneurship Theory and Practice, 32(4), 635-656.

Yang, B., Watkins, K. E., \& Marsick, V. J. (2004). The Construct of the Learning Organization: Dimensions, Measurement, and Validation. Human Resource Development Quarterly, 15(1), 31-55.

Zhang, D., Zhang, Z., \& Yang, B. (2004). Learning Organization in Mainland China: Empirical Research on its Application to Chinese State-Owned Enterprises. International Journal of Training and Development, 8(4), 258-273. https://doi.org/10.1111/j.1360-3736.2004.00213.x

Zhao, Y., Li, Y., Lee, S. H., \& Chen, L. B. (2011). Entrepreneurial Orientation, Organizational Learning, and Performance: Evidence From China. Entrepreneurship: Theory and Practice, 35(2), 293-317. https://doi.org/10.1111/j.15406520.2009.00359.x 